\title{
MANAGING MARGINS: OVERDESIGN IN HOSPITAL BUILDING SERVICES - ERRATUM
}

\section{A. Jones ${ }^{凶}$, C. Eckert and P. Garthwaite}

The Open University, United Kingdom

$\bigotimes$ darren.a.jones@open.ac.uk

doi: https://doi.org/10.1017/dsd.2020.151. Published by Cambridge University Press, 11 June 2020.

Figure 1 in the aforementioned article was published with several elements missing. The full correct figure is below:

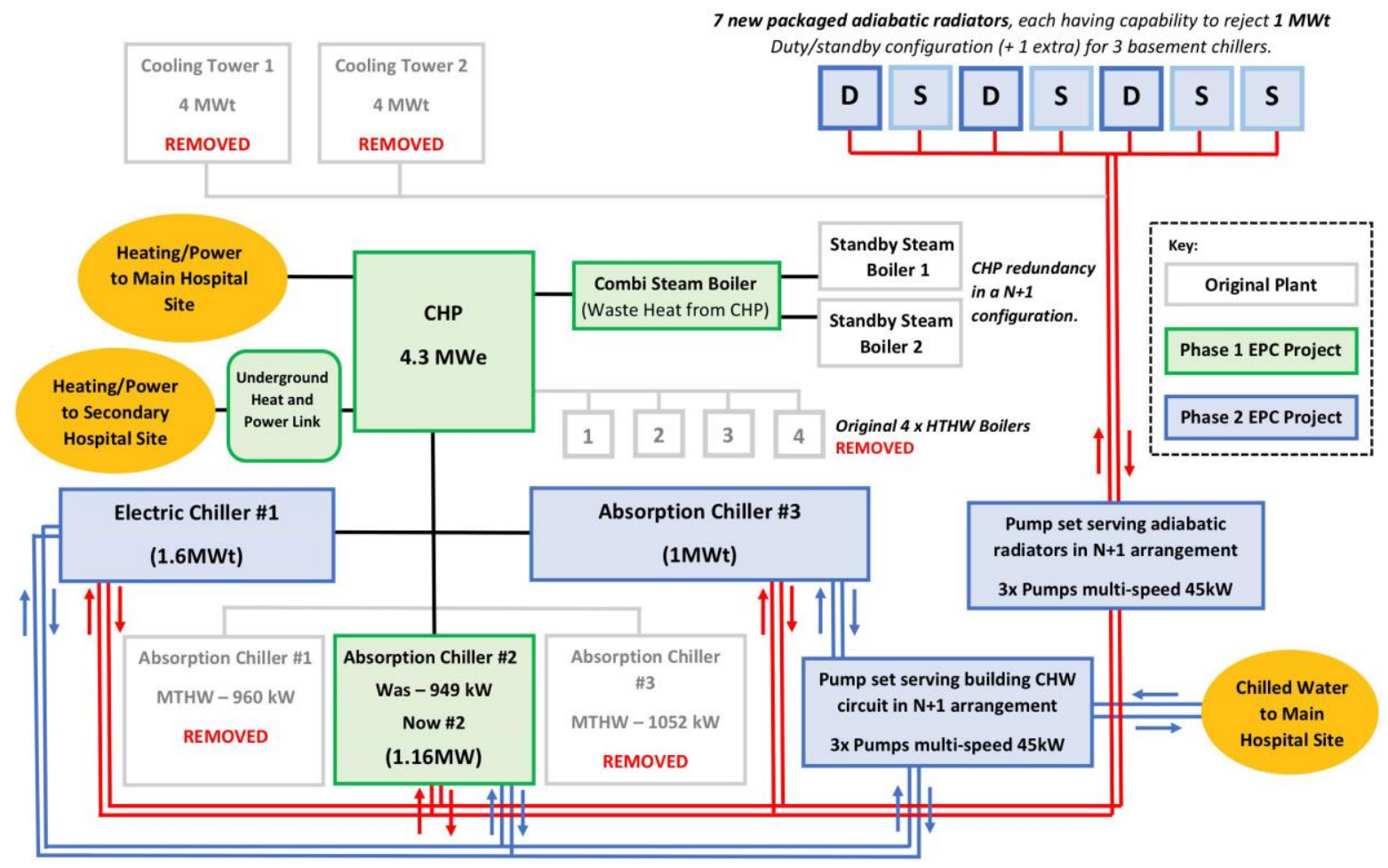

The Publisher apologises for this error.

\section{Reference}

Jones, D.A., Eckert, C. and Garthwaite, P. (2020), "Managing Margins: Overdesign in Hospital Building Services," in Proceedings of the Design Society: DESIGN Conference, Cambridge University Press, Vol. 1, pp. 215-224. https://doi.org/10.1017/dsd.2020.151 